\title{
SUB-SENTENTIAL LOGICAL FORM. ON ROBERT J. STAINTON'S WORDS AND THOUGHTS
}

Axel Arturo Barceló Aspeitia Instituto de Investigaciones Filosóficas Universidad Nacional Autónoma de México abarcelo@filosoficas.unam.mx

SUMMARY: Stainton argues $(2006,2001)$ that since sub-sentential speech acts lack the proper syntactic structure to have logical form, it is not from them that subsententially propositions conveyed derive their logical form. In this brief comment, I develop an argument for the claim that sub-sentential speech acts not only do have the proper syntactic structure, but that according to Stainton's own general pragmatic account of sub-sentential speech, they also satisfy all the criteria put forward by him to be the primary bearers of logical form.

KEY WORDS: syntax, speech acts, structure, pragmatics, argumentation

RESUMEN: Stainton arguye $(2006,2001)$ que, dado que los actos de habla suboracionales carecen de la estructura sintáctica apropiada para tener forma lógica, las proposiciones comunicadas de manera suboracional no derivan su forma lógica de ellos. En este breve comentario desarrollo un argumento a favor de la tesis de que los actos de habla suboracionales, no sólo tienen la estructura sintáctica apropiada, sino que - de acuerdo con la propia teoría pragmática general de Stainton sobre el habla suboracional - también satisfacen todos los criterios mencionados por el propio Stainton para ser los portadores básicos de forma lógica.

PALABRAS CLAVE: sintaxis, actos de habla, estructura, pragmática, argumentación

The central goal of Robert Stainton's Words and Thoughts (2006) is to argue that sub-sentential speech is a genuine phenomenon and to spell out some of its implications for our understanding of the relation between language and thought. By "sub-sentential speech", Stainton means full-fledged speech acts, where the speaker utters ordinary words and phrases, not embedded in any larger syntactic structure, and yet literally conveys a full proposition easily graspable by the hearer. Genuine sub-sentential speech is ipso facto non-elliptical, since what is produced in the speech act is not a semantically or syntactically elliptical sentence, but a sub-sentential linguistic unit. In other words, in genuine sub-sentential speech, the thing uttered not only sounds like a bare phrase, but actually is a bare phrase.

One of the implications Stainton wants to draw from sub-sentential speech is that there are things, like propositions, which have logical form and yet are neither expressions of natural language nor 
derive their logical form from that of other linguistic entities. This serves Stainton to refute a common implicit position he and Reinaldo Elugardo (2001) have previously referred to as "vernacularism", the view that logical forms are fundamentally assigned to linguistic entities like speech acts or expressions of natural language, and are only derivatively assigned to anything else: e.g. propositions, mental states, etcetera.

Even though I find Stainton's arguments against the primacy of sentential logical form over propositional logical form persuasive, I do not think they warrant his stronger claim that propositions have logical form non-derivatively. In this brief commentary, I will try to show my reasons for doubt. The plan for this text is as follows. First, I will sketch Stainton's argument against vernacularism. From this sketch I will identify the premise I will later challenge: that propositions conveyed sub-sententially cannot get their logical form derivatively from the sub-sentential speech act itself, because this kind of acts lack the proper syntactic structure to have logical form. In the remaining part of the text, I will try to develop an argument for the claim that sub-sentential speech acts not only do have the proper syntactic structure, but also satisfy the rest of the criteria put forward by Stainton to be the primary bearers of logical form.

\section{Anti-Vernacularism}

Stainton's argument against vernacularism (Stainton 2006, pp. 177190 ) is the first of several theoretical implications of sub-sentential speech discussed in the third and final part of his book. By then, Stainton has already established sub-sentential speech as a genuine phenomenon, i.e. he has given us ample evidence that we can use words and phrases to convey a proposition, without deploying internally any sentence of natural language that expresses it. Now, Stainton wants us to accept that these propositions conveyed subsententially may also have logical form. He bases his claim on a series of imaginary examples of sub-sentential argumentation, that is, conversations where premises or conclusions are conveyed subsententially. The examples are very plausible and even though one may have qualms regarding the formal nature of the exemplified entailments, ${ }^{1}$ more adequate examples would be just as easy to come

\footnotetext{
${ }^{1}$ Stainton's basic example concerns the entailment from something being red to it being coloured. For many, this may seem like a classical example of material inference, yet Stainton treats it as an enthymeme whose missing additional premise (that all red things are coloured) makes it formally valid.
} 
by. From the consideration of these examples, Stainton draws three important facts about sub-sententially conveyed propositions in general: (i) they can be true or false, (ii) they stand in entailment relations, and (iii) at least some of these entailment relations are formbased. From these three facts, it follows that what is conveyed in sub-sentential argumentation exhibits logical form.

For this to be an especially controversial conclusion, it is also necessary to show that the logical form of a proposition conveyed in sub-sentential speech is not derived from any other linguistic entity. It is pertinent therefore, to wonder what it takes for one thing's logical form to be derived from another's. There are certainly many senses in which one may talk about an object having a property derivatively from another object that has the same property. However, Stainton settles on a psychological conception. ${ }^{2}$ For him, an entity $a$ derives its logical form from that of $b$ if (A) $a$ and $b$ share the same logical form, and (B) it is psychologically impossible for us humans to recognize the entailment relations of $a$ without previously having grasped $b$ (Stainton 2006, p. 188). I will call (A) and (B) Stainton's "conditions for psychological primacy". Thus, all Stainton needs to show is that, in sub-sentential argumentation, an agent can grasp the logical form of the propositions conveyed without grasping any other linguistic entity that shares the proposition's logical form.

Stainton recognizes that propositions conveyed in sub-sentential argumentation can be expressed by sentences (of either natural or artificial languages). However, in sub-sentential speech in general (of which sub-sentential argumentation is a sub-kind), an agent can grasp propositions without grasping any sentence that expresses them (which is what would be required for the proposition to derive its logical form from that of a sentence). Therefore, the proposition conveyed sub-sententially cannot have its logical form derivatively from any sentence.

After ruling out sentences as primary purveyors of logical form, Stainton briefly discusses the possibility that propositions may get their logical form from other linguistic entities, like speech acts. However, this possibility is quickly dismissed. According to Stainton,

\footnotetext{
${ }^{2}$ This means that the validity of Stainton's thesis does not depend on whether or not the logical form of the proposition conveyed in sub-sentential speech is parasitic from that of any other linguistic entity in some other (explanatory or metaphysical) sense. In consequence, it is possible that the only way to explain why an entity $a$ has the logical form it has requires appealing to some other entity $b$ that has the same logical form, without $a$ deriving its logical form from $b$ in Stainton's psychological sense.
} 
speech acts do not have the proper syntactic structure to have logical form and thus, no proposition conveyed sub-sententially can get its logical form derivatively from them. Therefore, in general, propositions conveyed sub-sententially do not get their logical form derivatively from any linguistic entity.

\section{The Structure of my Counterargument}

Because of the way Stainton and Elugardo understand vernacularism, Stainton's claim that no proposition derives its logical form from any speech act plays a central role in his argument against it. It is not enough to show that not every proposition gets its logical form from some sentence. It is also necessary to show that it cannot get it from any other linguistic entity. And since Stainton accepts that "at least in a broad sense [a speech act] is clearly something linguistic" (p. 188), he must also show that a proposition conveyed sub-sententially cannot derive its logical form from that of the subsentential speech act itself. Otherwise, he would have only shown the already substantial claim that propositions cannot derive their logical form from sentences. (Notice, in passing, that this would be enough to show that "things other than natural language expressions can have logical forms [not] derivatively from the logical forms of natural language expressions". Stainton 2006, p. 22. My emphasis. See also Stainton and Elugardo 2001, p. 394.)

In this commentary, I want to challenge Stainton's dismissal of speech acts as plausible bearers of logical form. I will argue that not only do speech acts have the right kind of structure, but that Stainton's own pragmatic story of how propositions with logical form are conveyed in sub-sentential speech lends plausibility to the thesis that propositions get their logical form derivatively from them. If I am right, sub-sentential speech would not settle the question of whether propositions have logical form fundamentally or derivatively.

My argument runs as follows: First, I will try to show that (a) sub-sentential speech acts have the appropriate syntactic structure to have logical form, and (b) that sub-sentential speech acts have the same logical form as the proposition they convey. Now, since Stainton's pragmatic story of how propositions are conveyed subsententially recognizes that the hearer cannot grasp the proposition conveyed in a sub-sentential speech act without grasping the speech act as well, the conjunction of this recognition with the previous two claims will be enough to show that sub-sentential speech acts satisfy Stainton's conditions for psychological primacy. In consequence, if it 
can be shown that (A) and (B) hold for sub-sentential speech acts, the question whether the proposition conveyed in a sub-sentential speech act gets its logical form from the speech act itself would remain open, and vernacularism might yet be salvaged.

\section{The Logical Form of (Sub-Sentential) Speech Acts}

Sub-sentential speech acts are complex acts. They involve many elements. Besides the semantic properties of expressions, different features of the context and the way the expressions are uttered contribute to the speech act's capacity for conveying the information it conveys. These elements may be classified and structured in many ways. The relevant question for our discussion is whether or not they can be structured in a syntactic way, i.e. if any of the ways we may decompose a (sub-sentential) speech act may be rightfully called syntactic. Stainton only finds one such way: to consider the syntax of whatever was uttered in the speech act as the speech act's syntax. Now, even though the phrases uttered in sub-sentential speech certainly exhibit syntactic structure, this structure does not match the logical form of the full propositions they are used to convey. Thus, if we identified the syntax of the speech act with the syntax of the thing uttered, the proposition could not derive its logical form from it. However, Stainton fails to look further into the speech act's structure to find something else that might also be called its syntax. My contention is that, if we consider as constituents of speech acts both the thing uttered (and its constituents) and whatever other elements are used to convey the functions and arguments that combined yield the asserted proposition, the way these constituents are structured may rightfully be called the speech act's syntax.

In order to see that sub-sentential speech acts have the appropriate syntactic structure to have logical form, it is enough to notice that sub-sentential speech acts have syntactic constituents beyond those belonging to the expressions uttered, and that these constituents are combined according to strict syntactic rules. This might require extending the notion of "syntactic constituent" beyond its usual domain of linguistic expressions to cover any element of a speech act that contributes to communicating the proposition conveyed in such an act. Of course, this requires completely ignoring the usual distinctions between syntax, semantics and pragmatics. However, the move is warranted by the strong similarities between the semantic and pragmatic elements involved in sub-sentential speech, at least according to Stainton's own theory. 
According to Stainton's general pragmatic account, in sub-sentential speech phrases are used with their regular meanings. Since these meanings are not propositions, a pragmatic mechanism is set into gear to determine the proposition the speaker intended to convey. An expression need not be of semantic type $<\mathrm{t}>$ to be used to perform a full-fledged speech act; however it must be used in such a context that the hearer may still grasp a full proposition without needing to complete a sentence in her mind. Context must provide the proposition's missing elements, according to the uttered expression's semantic type. If the phrase uttered is of type $\langle e, t\rangle$, for example, the context must make salient an entity that may serve as argument to the function provided by the phrase. In other words, phrase and context must provide adequate arguments and functions, capable of combining into a full proposition (Stainton 2006, p. 157).

In this story, the proposition's constituents are the different elements the hearer needs to combine to recover the communicated proposition. Some of them come from the uttered expression, while others come from the context. Yet, no matter where they come from, once they are combined into a proposition, they work seamlessly together as logical components. Commenting on Alice's example, for example, Stainton writes:

Take what Alice got across. It's about an object, the pen, to the effect that it is red. This entails by the structure of subject-predicate predication, that something is red. (Note: by "predication" here I mean the logical relation, not the one specific to natural language.) $[\ldots]$ The entailment holds regardless of what that object happens to be: it's the structure of $\operatorname{Red}(o)$ together with $(x)(\operatorname{Red}(x) \rightarrow \operatorname{Colored}(x))$ that yields it. (Stainton 2006, p. 187; the first emphasis is mine.)

In this example, the structure-determining constituents of the proposition expressed by Alice's utterance of "Red" are both the property red expressed by "Red" and the contextually conveyed pen. The first one plays the role of predicate, and the second of subject. This is what it means to say that they are logically related in predication. The way they are combined is what determines the latter's structure. This combination of elements - that takes place, in the hearer's mind, at the level of content - is what determines the proposition's structure and, ultimately, its logical form.

Notice how the logical form of the conveyed proposition corresponds to the way the different contributions of each of the speech act's constituents combine. The proposition conveyed by Alice's 
complex act is of the subject-predicate form precisely because the phrase she uttered conveyed the predicate while her ostensive act conveyed the subject. Just as entity and property combine to form the proposition, utterance and ostension combine to form the speech act. The way the speech act is composed fully reflects the structure of the proposition. This suggests that the composite of the utterance and the ostension is a different kind of composite - different both from the proposition and from any sentence that may be used to express it - whose constituents correspond to those of the proposition, and whose logical structure mirrors the proposition's logical form.

If we take speech acts as syntactically composed by the expression uttered plus all the contextual elements that contribute to the grasping of the proposition's constituents, we would have a linguistic entity that not only would share its logical form with the proposition it is performed to convey, but one that could not be easily dismissed as not playing an important role in the grasping of that proposition. Therefore, unlike any other sentence that may also share the proposition's logical form, the speech act is something the hearer grasps before determining the entailment relations of the proposition conveyed. As such, it satisfies all of Stainton's constraints for being the primary bearer of logical form.

Notice that, in accordance with Stainton's second condition (B) for logical primacy, the conveyed proposition can derive its logical form from that of the sub-sentential speech act, even if one could not, psychologically speaking, grasp the logical form of the speech act without grasping the logical form of the proposition conveyed. After all, the logical form of the speech act is the logical form of the proposition conveyed. All that is required is for the hearer to grasp the speech act itself, before recognizing the entailment relations of the proposition conveyed. ${ }^{3}$

\section{On Composition}

Should anyone still be suspicious of the notion that speech acts are composed of constituents of various Montogovian types, let me dispel some common misconceptions about this kind of composition. Most of all, I find it important not to confuse a linguistic entity's constituents with its physical parts. At least since Frege's famous seed

\footnotetext{
${ }^{3}$ I thank one of Crítica's anonymous referees for calling my attention to this point.
} 
metaphor, ${ }^{4}$ it is commonly recognized that logical components are not physical parts. ${ }^{5}$ Neither every component is a part, nor every part, a component. Otherwise, abstract objects could not be structured (Mills 2006). Yet, we commonly speak about the structure of abstract entities like the English language or the natural numbers. Composition, after all, is analysis-relative. What the components of something are depends on the purposes of its analysis. "Components/constituents", "structure/form" 6 and "analysis" are deeply interconnected notions, so that it is impossible to make sense of one without the others. ${ }^{7}$ To analyze is to reveal the structure and components of a complex entity or system, ${ }^{8}$ so that its components are those elements that contribute, or are relevant, to explaining why the system has a certain property or properties. In other words, for something to be a component of a system is to have what Cummins (1975) called a "function" in that system. Depending on what properties we are trying to explain about the object, we may analyze it in different ways and, therefore, come up with different sets of components. The electrical components of a car, for example, are those that are relevant to explain the electrical working of such a mechanism. Each of them, therefore, has a function that contributes to the car's electrical system working the way it does. These components are different from, say, its hydraulic or mechanical components. Something is a mechanical component of a car if it explains, through its interaction with the other mechanical components, the mechanical functioning of the car. Not every part of the car is relevant for this purpose and, therefore, not every part of the car is a mechanical component. Think of the seat covers or the license plates. They play no mechanical role and therefore do not qualify as mechanical components. Yet they are still parts of the car. Ditto for the syntactic, semantic or logical components of linguistic entities. What makes something a logical constituent of a sentence, for example, is not so much that it is one of

${ }^{4}$ According to which, logical consequences are contained "as plants are contained in their seeds, not as beams are contained in a house" (Frege 1950, p. 101).

${ }^{5}$ In order to avoid further misunderstandings, let me make an artificial distinction between "parts", which I shall use to talk about physical parts, and "components", which I will use to refer to the things that are structured into complex wholes.

${ }^{6} \mathrm{I}$ will use both terms in these pairs as synonyms.

${ }^{7}$ A more complete development of the intimate relations between these notions is the central purpose of my forthcoming book. I hope these brief remarks serve for now.

${ }^{8}$ I will use the term "system" to make reference to any complex entity susceptible of analysis. 
its physical parts (or a part of one of its physical tokens), but that it is an element necessary to systematically account for the sentence's logical properties (the same holds for propositions, especially if they are abstract objects with no physical parts). Similarly, the semantic components of a sentence are those that explain its semantic profile. The syntactic form of a sentence, accordingly, is nothing but the specification of how its semantic components contribute to it having the semantic properties it has. This account can be easily extended to a speech act, so that its constituents are not its physical parts, but those entities required to explain why it has the syntactic, semantic or logical properties it has.

Notice that, even if they are all physical objects, the set of constituents of a system need not constitute a physically identifiable unit. Constituents may be physically related, yet not physically united into a larger physical object. Consider the human digestive system. The organs that constitute it are physical objects. They are physically related and physically interact with each other within the system. Yet, we would not say that the digestive system is a big physical object (so that the intestines, the stomach, etc. are its physical parts). When we say that a system is complex, rather than simple, we do not mean to imply that it is a large object with physically identifiable parts. All it takes for something to be structurally complex is to have analytically identifiable components, each one with a particular function or role within it. Thus the logical components of a speech act (if they exist, as I argue they do) need not be identified with its physical parts in any substantial sense.

\section{Conclusions}

Let me recapitulate my argument. My first substantial premise was that sub-sentential speech acts have syntactic constituents beyond the expressions uttered in them. I base this claim on two features of Stainton's general pragmatic picture: first, the expressions uttered in sub-sentential speech have meanings in themselves, and second, other elements required to grasp the proposition conveyed are obtained from the speech act's context. This means that both the expression uttered and the contextual elements in the speech act play a similar role: they both contribute something determinate to the speech act's content, i.e. they both convey determinate objects or functions that end up becoming constituents of the conveyed proposition. This seems enough to consider them both as constituents of the speech act. 
Then, I needed to show that these constituents were syntactically structured. This I also based on Stainton's general pragmatic story. According to Stainton, the proposition conveyed in sub-sentential speech is grasped through the combination of the entities and functions grasped from the speech act's constituents defined above. This means that the speech act's communicated content is composed of the entities conveyed by its constituents, either semantically or pragmatically. Furthermore, this composition obeys the rules of wellformedness derived from the constituents' semantic types. In Stainton's example, Alice's act of uttering "red" is of a certain semantic type (relative to the argumentation context), and her act of demonstrating her pen is also of a certain, but different semantic type (relative to the same context). According to Stainton's general pragmatic story, both the expression uttered and the contextual elements involved are all of specific types. In order to combine into a full proposition, these types must match adequately. This must be enough to ground the claim that the way the speech act's constituents are structured is syntactic.

Finally, it is easy to see that the syntactic composition of the speech act matches the logical form of the proposition conveyed. Thus, the speech act's logical form is not different from that of the proposition conveyed. This gives us all the premises necessary to show that the sub-sentential speech act itself satisfies Stainton's conditions for logical primacy: (A) speech act and proposition conveyed share the same logical form, and (B) it is psychologically impossible for us humans to recognize the entailment relations of the conveyed proposition without previously having grasped the speech act as well.

To conclude, sub-sentential speech acts have semantic constituents beyond those of the expression uttered in them. The hearer grasps the proposition conveyed by combining the meaning of the uttered phrase with other contextually salient objects or arguments. This combination gives the proposition its logical form and, therefore, at least in this sense, one can say that propositions conveyed subsententially may have their logical form derivatively, not from a sentence, but from the speech act itself. ${ }^{9}$

\footnotetext{
${ }^{9}$ Thanks to Robert Stainton, Lenny Clapp, and two anonymous referees for their useful comments and recommendations. This research received generous support from PAPIIT projects IN 401106 "¿Qué es el análisis?", and IN 401707 "Problemas conceptuales de las bases biológicas de la mente y del lenguaje".
} 


\section{REFERENCES}

Cummins, R., 1975, "Functional Analysis", The Journal of Philosophy, vol. 72, pp. 741-765.

Elugardo, R., 2001, "Logical Form and the Vernacular", Mind and Language, vol. 16, no. 4, pp. 393-424.

Frege, G., 1950, The Foundations of Arithmetic, Blackwell, Oxford.

Mills, E., 2008, "Are Analytic Philosophers Shallow and Stupid?", The Journal of Philosophy, vol. 105, no. 6, pp. 301-319.

Stainton, R.J., 2006, Words and Thoughts: Subsentences, Ellipsis and the Philosophy of Language, Oxford University Press, Oxford.

Received: January 16, 2009; revised: December 28, 2009; accepted: May 24, 2010. 